EPJ Web of Conferences 82, 01023 (2015)

DOI: $10.1051 /$ epjconf/20158201023

(C) Owned by the authors, published by EDP Sciences, 2015

\title{
Ignition of organic explosives by a laser pulse
}

\author{
Vadim A. Dolgachev ${ }^{1}$ and Alexander V. Khaneft ${ }^{1,2, a}$ \\ ${ }^{1}$ Kemerovo State University, 650043 Kemerovo, Russia \\ ${ }^{2}$ National Research Tomsk Polytechnic University, 634050 Tomsk, Russia
}

\begin{abstract}
The modeling of initiation of PETN, RDX, HMX and TATB by a short laser pulse is done in this work. The heat-conduction equation was solved in a cylindrical coordinate system taking into account multiple reflection of the light beam, zero-order exothermic reaction, and melting. The calculation results for PETN are in satisfactory agreement with experiment. Calculations have shown that with an identical coefficient of absorption the most sensitive is PETN, and the most heat-resistant is TATB.
\end{abstract}

\section{Introduction}

Recently there has been a considerable increase in the number of papers on both experimental studies and numerical simulation of the conditions of explosive initiation by laser pulse [1-7]. It is caused by both the development of the new explosive initiation methods and scientific interest in defining the initiation mechanism in order to regulate the threshold energy of initiation purposefully.

Organic explosives have high transparency at the first harmonic wavelength of the pulsed neodymium laser $(\lambda=1.06 \mu \mathrm{m})$ [8]. Consequently, the high-power laser is necessary for their initiation from an open surface by the high light pulse in this spectral range [9]. Usually, a sample is covered with a transparent substrate to reduce the ignition threshold. The mechanism of reducing the ignition threshold energy by the substrate is treated differently by different authors. For example, according to paper [10] the substrate is believed to prevent the gas-dynamic unloading of the explosives, which leads to the reducing the ignition threshold. According to [11], the absorption coefficient $\alpha$ of PETN crystals at the wavelength $\lambda=1.06 \mu \mathrm{m}$ is about $0.033 \mathrm{~cm}^{-1}$. If the dense energy of the laser pulse is $W \sim 15 \mathrm{~J} / \mathrm{cm}^{2}$, the heating of the explosive can be ignored. It means that the gas-dynamic unloading is impossible. Paper [12] experimentally proves that the ablation of the substrate and the optical breakdown on the boundary of the substrate lead to reducing the ignition threshold of the explosive, which are transparent for the pulsed neodymium laser.

The objective of the current paper is to simulate the ignition of organic explosives (PETN, RDX, HMX, TATB) by the laser beam in the transparency area in order to determine the ordinary dependence of ignition threshold.

\footnotetext{
${ }^{a}$ Corresponding author: khaneft@kemsu.ru
}

This is an Open Access article distributed under the terms of the Creative Commons Attribution License 4.0, which permits unrestricted use, distribution, and reproduction in any medium, provided the original work is properly cited. 


\section{Problem statement}

We write the heat conduction equation in cylindrical coordinates taking into account melting and multiple light reflection from the opposite sides of the sample:

$$
\begin{aligned}
\rho\left[c+H_{f} \delta\left(T-T_{f}\right)\right] \frac{\partial T}{\partial t}= & \lambda\left(\frac{1}{r} \frac{\partial}{\partial r}\left(r \frac{\partial T}{\partial r}\right)+\frac{\partial^{2} T}{\partial z^{2}}\right) \\
& +\alpha\left(1-R_{1}\right) I_{0}(t) \exp \left(-\alpha z-\frac{r^{2}}{r_{0}^{2}}\right) \frac{\left[1+R_{2} \exp (2 \alpha(z-L))\right]}{\left[1-R_{1} R_{2} \exp (-2 \alpha L)\right]} \\
& +\rho Q Z \exp \left(-\frac{E}{R T}\right) .
\end{aligned}
$$

Equation (1) has the following initial and boundary conditions

$$
\begin{gathered}
T(r, z, 0)=T_{0},\left.\frac{\partial T}{\partial r}\right|_{r=0}=\left.\frac{\partial T}{\partial r}\right|_{r=R_{0}}=0, \\
\left.\frac{\partial T}{\partial z}\right|_{z=0}=\left.\frac{\partial T}{\partial z}\right|_{z=L}=0 .
\end{gathered}
$$

Here $H_{f}$ is the latent heat of melting; $\delta\left(T-T_{f}\right)$ is the delta-function; $R_{0}$ and $L$ are the radius and length of the cylindrical sample; $T_{0}$ is the initial temperature; $\lambda, c$ are thermal conductivity coefficient and specific heat; $\rho$ is density; $Q, Z, E$ are the heat of the reaction per the mass unit of the material, the frequency factor and the activation energy of decomposition rate; $R$ is the universal gas constant; $r_{0}$ is the radius of the beam; $I_{0}(t)$ is the energy flux density at the center of the beam; $R_{1}$ is the surface reflection coefficient at the entrance of light beam to the sample; $R_{2}$ is the reflection coefficient of the back surface at the exit of the light beam from the sample.

The energy flux density at the center of the beam is given by

$$
I_{0}(t)=\frac{W}{6 \tau_{m}}\left(4 t / \tau_{m}\right)^{4} \exp \left(-\frac{4 t}{\tau_{m}}\right)
$$

where $\tau_{m}$ is the duration of the leading edge of the pulse, related to the pulse duration determined at the half-high by the equation $\tau_{i}=1.19 \tau_{m}$. Besides,

$$
\int_{0}^{\infty} I(t) d t=W .
$$

\section{Results and discussion}

The heat conductivity equation is numerically solved using an implicit difference scheme. The difference equations are solved by the sweep method. Coordinate steps are variable. Energy conservation law is observed accurate within $\sim 3.2 \%$. The calculations are carried out at the following kinetic and thermalphysic parameters of the explosive: PETN $-E=196.6 \mathrm{~kJ} / \mathrm{mol}, Z=6.3$. $10^{19} \mathrm{~s}^{-1}, Q=1.26 \mathrm{MJ} / \mathrm{kg}, \lambda=0.25 \mathrm{~W} /(\mathrm{m} \cdot \mathrm{K}), T_{f}=413 \mathrm{~K}[13], c=1255 \mathrm{~J} /(\mathrm{kg} \cdot \mathrm{K})[14], \rho=1.77$. $10^{3} \mathrm{~kg} / \mathrm{m}^{3}$ [15], $H_{f}=193 \mathrm{~kJ} / \mathrm{kg}$ [16]; RDX $-E=197.3 \mathrm{~kJ} / \mathrm{mol}, Z=2.02 \cdot 10^{18} \mathrm{~s}^{-1}, Q=2.1 \mathrm{~J} /$ $\mathrm{kg}, \lambda=0.105 \mathrm{~W} /(\mathrm{m} \cdot \mathrm{K}), T_{f}=476 \mathrm{~K}[13], c=1000 \mathrm{~J} /(\mathrm{kg} \cdot \mathrm{K})[15], \rho=1.82 \cdot 10^{3} \mathrm{~kg} / \mathrm{m}^{3}$ [17], $H_{f}=235.5 \mathrm{~kJ} / \mathrm{kg}[16] ; \mathrm{HMX}-E=220.8 \mathrm{~kJ} / \mathrm{mol}, Z=5.0 \cdot 10^{19} \mathrm{~s}^{-1}, Q=2.1 \mathrm{MJ} / \mathrm{kg}, \lambda=0.293 \mathrm{~W} /$ $(\mathrm{m} \cdot \mathrm{K}), T_{f}=558 \mathrm{~K}[13], c=1250 \mathrm{~J} /(\mathrm{kg} \cdot \mathrm{K})[18], \rho=1.9 \cdot 10^{3} \mathrm{~kg} / \mathrm{m}^{3}$ [17], $H_{f}=192.46 \mathrm{~kJ} / \mathrm{kg}$ [19]; TATB $-E=250.9 \mathrm{~kJ} / \mathrm{mol}, Z=3.8 \cdot 10^{19} \mathrm{~s}^{-1}, Q=2.51 \mathrm{MJ} / \mathrm{kg}, \lambda=0.418 \mathrm{~W} /(\mathrm{m} \cdot \mathrm{K}), T_{f}=623 \mathrm{~K}$ [13], $c=1250 \mathrm{~J} /(\mathrm{kg} \cdot \mathrm{K}), \rho=1.93 \cdot 10^{3} \mathrm{~kg} / \mathrm{m}^{3}[15], H_{f}=192.46 \mathrm{~kJ} / \mathrm{kg}$. 


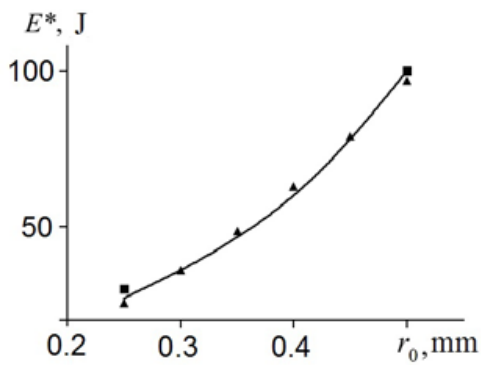

Figure 1. The dependence of PETN initiation threshold energy on the radius of the light beam: line - numerical calculation at $\alpha=0.065 \mathrm{~cm}^{-1}, \boldsymbol{\square}$ - experiment [9], $\mathbf{\Delta}$ - calculation on criterion.

Table 1. Critical energy density of organic explosive initiation by the laser pulse.

\begin{tabular}{|l|l|l|l|l|}
\hline Explosive & PETN & RDX & HMX & TATB \\
\hline$W^{*}, 10^{8} \mathrm{~J} / \mathrm{m}^{2}$ (criterion) & 1.26 & 1.34 & 1.63 & 1.96 \\
\hline$W^{*}, 10^{8} \mathrm{~J} / \mathrm{m}^{2}$ (calculation) & 1.35 & 1.42 & 1.72 & 2.07 \\
\hline
\end{tabular}

The heat of melting for TATB is determined from empirical formula

$$
H_{f} / T_{f} \approx C,
$$

where $C \approx 0.43 \mathrm{~kJ} /(\mathrm{kg}] \cdot \mathrm{K}) . C$ is estimated by averaging $H_{f} / T_{f}$ for PETN, RDX and HMX. Reflection and absorption coefficients for all the explosives are considered to be equal: $R_{1}=R_{2}=$ $0.036, \alpha=0.065 \mathrm{~cm}^{-1}$. Coefficient $\alpha$ is selected within reason to describe the experiment on PETN initiation [9].

Figure 1 shows the numerical results of the heat conductivity solution. As it is presented in Fig. 1, the critical density $\left(E^{*}=\pi r_{0}^{2} W^{*}, r_{0}=0.25 \mathrm{~mm}\right.$ ) qualitatively correlates with both the experiment and the critical energy of ignition, defined from the criterion [20]:

$$
\begin{aligned}
z_{1} \rho Q Z \exp \left(-\frac{E}{R T_{m}}\right)=\lambda \frac{\Delta T_{m}}{F(\gamma)} \\
\times\left\{\alpha \text { th }\left[\alpha L-\frac{1}{2} \ln \left(R_{2} F^{2}(\gamma)\right)\right]+\frac{4 z_{1}}{r_{0}^{2}}\right\}, \\
W^{*}=\frac{\left[1-R_{1} R_{2} \exp (-2 \alpha L)\right]}{\left[1+R_{1} \exp (-2 \alpha L)\right]} \\
\times\left[\frac{c \rho \Delta T_{m}}{\alpha\left(1-R_{1}\right)}+\frac{\rho H_{f}}{\alpha\left(1-R_{1}\right)}\right],
\end{aligned}
$$

where

$$
\gamma=R T_{m} / E, F(\gamma)=(1+\gamma) /\left(1-\gamma T_{0} / \Delta T_{m}\right), z_{1}=\alpha^{-1} \ln F(\gamma) .
$$

The relative error in defining threshold energy of the organic explosive initiation by the laser pulse from formulae (4), (5) and estimated from the solution of the heat conductivity equation is $\sim 5.5 \%$. Table shows critical energy density of organic explosive initiation by the laser pulse. Table demonstrates that PETN is the most sensible to initiation by the laser pulse and the most heat-resistant is TATB. 


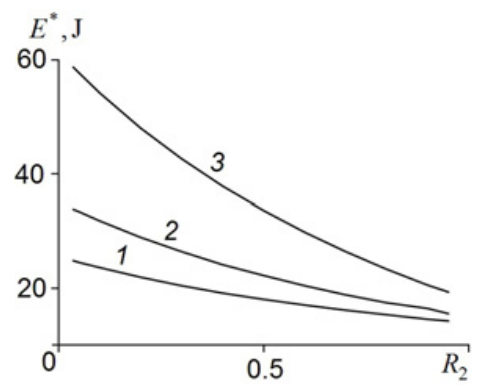

Figure 2. The dependence of PETN ignition critical energy on the coefficient of reflection $R_{2}$ at $R_{1}=0.036$ (1), 0.3 (2) and $0.6(3)$.
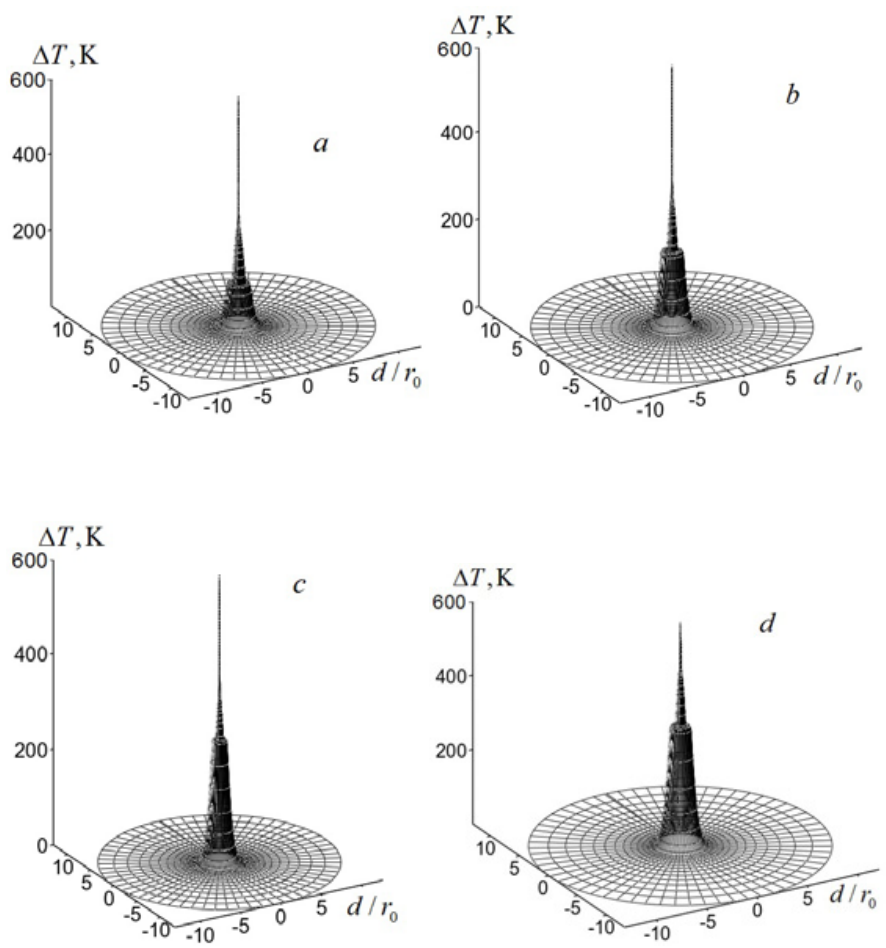

Figure 3. Radial distribution of temperature $\Delta T$ on the surface: PETN $(a)\left(W=1.4 \cdot 10^{8} \mathrm{~J} / \mathrm{cm}^{2}, t=5.9 \cdot 10^{-4} \mathrm{~s}\right)$; $\operatorname{RDX}(b)\left(W=1.55 \cdot 10^{8} \mathrm{~J} / \mathrm{cm}^{2}, t=2.6 \cdot 10^{-4} \mathrm{~s}\right) ; \operatorname{HMX}(c)\left(W=1.8 \cdot 10^{8} \mathrm{~J} / \mathrm{cm}^{2}, t=5.1 \cdot 10^{-4} \mathrm{~s}\right) ;$ TATB $(d)$ $\left(W=2.2 \cdot 10^{8} \mathrm{~J} / \mathrm{cm}^{2}, t=5.3 \cdot 10^{-4} \mathrm{~s}\right)$.

Figure 2 shows the calculation results of critical ignition energy $E^{*}$ for PETN (formulae (3), (4)) depending on the reflection coefficient of the back of the sample. The calculations are carried out at $r_{0}=0.25 \mathrm{~mm}$ and the reflection coefficient $R_{1}=0.036$ (curve 1), 0.3 (curve 2) and 0.6 (curve 3). The reflection coefficient $R_{2}$ is changed from Fresnel reflection coefficient $\left(R_{2}=0.036\right)$ to the reflection coefficient of metal $\left(R_{2}=0.95\right)$. Figure 2 illustrates that the higher the reflection coefficient $R_{1}$ is, the wider the limits are, within which the energy of organic explosive initiation $E^{*}$ by the laser pulse can be varied by changing the reflection coefficient $R_{2}$.

Figure $3(a, b, c$ and $d$ ) presents the calculation results of the radial distribution of temperature $\Delta T$ at the origin of coordinates for PETN, RDX, HMX and TATB. 
These figures show that the ignition of organic explosives starts from the surface. Thus, heat imbalance, caused by Arrhenius nonlinearity, leads to the ignition of PETN, RDX, HMX and TATB from the surface in spite of almost insignificant gradient of temperature along the axis $z$, conditioned by the smallness of light absorption coefficient.

\section{Conclusions}

1. Common dependency of organic explosives (PETN, RDX, HMX and TATB) ignition established. Most sensitive to the initiation by a laser pulse is PETN, and the most heat-resistant is TATB.

2. Although there is a slight temperature gradient along the $\mathrm{z}$ axis, the violation of thermal equilibrium due to the Arrhenius nonlinearity leads to the ignition of organic explosives by a laser pulse from the surface.

3. Calculations favor the thermal initiation mechanism of PETN by a laser pulse of a nanosecond duration.

\section{References}

[1] V.E. Zarco, V.N. Simonenko, P.I. Kalmykov, A.A. Kvasov, E.N. Chesnokov, K.E. Kuper, Combust. Expl. Shock Waves 45, 752 (2009)

[2] E.D. Aluker, N.L. Aluker, G.M. Belokurov, A.G. Krechetov, B.G. Loboiko, D.R. Nurmukhametov, A.V. Tupitsyin, V.P. Filin, Russ. J. Phys. Chem. B 4, 63 (2010)

[3] R.S. Burkina, V.V. Medvedev, O.V. Khrenova, Combust. Expl. Shock Waves 46, 554 (2010)

[4] O.V. Vysokomornaya, G.V. Kuznetsov, P.A. Strizhak, J. Eng. Thermophys. 19, 85 (2010)

[5] E.V. Duginov, A.V. Khaneft, Combust. Expl. Shock Waves 47, 490 (2011)

[6] A.V. Khaneft, E.V. Duginov, Combust. Expl. Shock Waves 48, 699 (2012)

[7] I.G. Assovskii, V.V. Kozynda, Docl. Akad. Nauk 442, 771 (2012)

[8] L.G. Strakovskii, Combust., Expl., Shock Waves 21, 39 (1985)

[9] A.I. Bykhalo, E.V. Zhuzhukalo, N.G. Kovalskii, A.N. Kolomiyski, V.V. Korobov, V.V., Rozhkov, A.I. Yudin, Combust., Expl., and Shock Waves 21, 481 (1985)

[10] V.I. Tarzhanov, A.D. Zinchenko, V.I. Sdobnov, B.B. Tokarev, A.I. Pogrebov, A.A. Volkova, Combust., Expl., Shock Waves 32, 454 (1996)

[11] A.M. Baranovskii, Combust., Expl., Shock Waves 26, 307 (1990)

[12] K. Nagayama, Y. Kotsuka, M. Nakahara, S. Kubota, S., Sci. and Technol. of Energetic Mater 66, 416 (2005)

[13] Explosion Physics (Nauka, Moscow, 2002). [in Russian]

[14] A.V. Belyaev, V.K. Bobolev, A.I. Korotkov, A.A. Sulimov, S.V. Chuiko, Transition of condensed systems from ignition to explosion (Nauka, Moscow, 1973). [in Russian]

[15] Detonation and Explosives, collection of articles, (Mir, Moscow, 1981). [in Russian]

[16] F.A. Baum, A.S. Derzhavec, N.N. Sanasaryan, Thermoresistant explosives and their effect in deep wells (Nedra, Moscow, 1969)

[17] R. Shall, "Physics of a detonation, in "Physics of high energy density" (Mir, Moscow, 1974)

[18] I.G. Assovskiy, Physics of combustion and interior ballistics (Nauka, Moscow, 2005)

[19] V.A. Strunin, L.I. Nikolaeva, G.B. Manelis, Russ. J. Phys. Chem. B 4, 627 (2010)

[20] A.V. Khaneft, V.A. Dolgachev, Combust. Expl. Shock Waves 50, 105 (2014) 